\title{
Preparation of Zirconia Ceramics with Straight and Uniform-Sized Channels
}

\author{
Akio KATO and Hiroaki MIZUMOTO* \\ Department of Applied Chemistry, Faculty of Engineering, Kyushu University \\ 10-1, Hakozaki 6-chome, Higashi-ku, Fukuoka-shi 812 \\ * Toyo Soda Manufacturing Co., Ltd.
}

直細孔をもつジルコニアセラミックスの製造

加藤昭夫・水本浩昭*

( 九州大学 工学部 応用化学科)

Firing of zirconia $\left(\mathrm{Y}_{2} \mathrm{O}_{3}: 3\right.$ mol\%) powder-carbon fiber compact in air at $1500^{\circ}-1600^{\circ} \mathrm{C}$ gave a zirconia ceramics with straight channels of uniform diameter.

[Received February 18, 1986]

Key-words : Straight channel, PSZ

\section{Introduction}

In ceramic filters with a pore size in the micrometer range, channels or capillaries consist of a zigzag and three-dimensional network of intergranular pores. The present authors reported that the firing of an alumina powder-carbon fiber compact in air at $1500^{\circ}-1600^{\circ} \mathrm{C}$ gave an alumina ceramics with straight channels of uniform diameter and that the diameter could be controlled by the size of carbon fiber ${ }^{1}$. In the present paper, we applied this method to the preparation of zirconia ceramics with straight channels.

\section{Experimental}

The starting oxide was $3 \mathrm{~mol} \% \quad \mathrm{Y}_{2} \mathrm{O}_{3}-\mathrm{ZrO}_{2}(3$ Y.PSZ) from Toyo Soda Manuf. Co., Ltd. The average particle size was $0.06 \mu \mathrm{m}$ (Fig. 1). The carbon fiber was Toreca $300-99 \mathrm{~B}$ from Toray Industries, Inc. with the diameter of $5 \mu \mathrm{m}$. The fiber was cut into 1-2 $\mathrm{mm}$ long filaments. The filaments $(7.4$ vol\%) were mixed with $3 \mathrm{Y} \cdot \mathrm{PSZ}$ powders. After addition of ethanol, ultrasonic agitation was used to disperse the carbon filaments. After evaporation of the ethanol to the degree at which the mixture paste had a suitable hardness for extrusion, the paste was formed into noodles of $1.5 \mathrm{~mm}$ diameter with an injector in order to align the carbon filaments. The noodles were cut to about $25 \mathrm{~mm}$ in length. Several pieces of them were stacked in parallel in a box and, with addition of a small amount of ethanol, compacted into a specimen of $4 \times 3 \times 26 \mathrm{~mm}$. After drying, the specimen was isostatically pressed mainly at $3.0 \mathrm{t} / \mathrm{cm}^{2} .3 \mathrm{Y} \cdot \mathrm{PSZ}$ compacts without carbon filaments were also prepared by the same procedure. The firing was done on the $3 \mathrm{Y}$.PSZ powder bed in an alumina boat in air at $1400^{\circ}-1600^{\circ} \mathrm{C}$. In order to estimate the density of the $3 \mathrm{Y} \cdot \mathrm{PSZ}$ matrix, $3 \mathrm{Y} \cdot \mathrm{PSZ}$ compacts without carbon filaments were fired at the same time. The density of the sintered material was measured by a water immersion method.

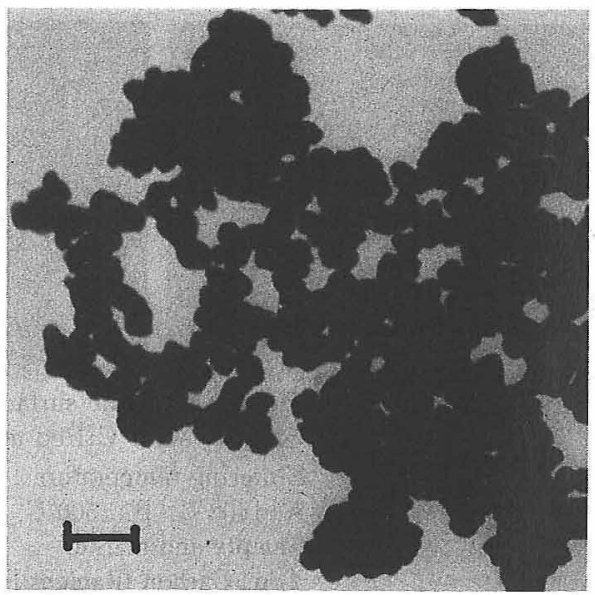

Fig. 1. $3 \mathrm{~mol} \% \mathrm{Y}_{2} \mathrm{O}_{3}-\mathrm{ZrO}_{2}$ particles. Marker : $0.2 \mu \mathrm{m}$ 


\section{Results}

Carbon filaments (7.4 vol\%)-3 Y.PSZ and carbon filament-free $3 \mathrm{Y} \cdot \mathrm{PSZ}$ were fired at $1400^{\circ}-1600^{\circ} \mathrm{C}$ for $2 \mathrm{~h}$ in air. The relative density is shown in Fig. 2. The fracture surfaces are shown in Fig. 3. As can be seen, the present method gives ceramics with straight channels with a uniform diameter. The size of the channels, $5.0-6.5 \mu \mathrm{m}$, is close to that of the original carbon filaments. Since both PSZ's have a similar microstructure, the density of the matrix in the carbon filament-PSZ is considered to be close to that of carbon filament-free PSZ.

The effect of firing time on the relative density was small after $1 \mathrm{~h}$ at $1500^{\circ} \mathrm{C}$. When carbon filament-free $\mathrm{PSZ}$ was heated up to $1500^{\circ} \mathrm{C}$ at ca. $8^{\circ} \mathrm{C} / \mathrm{min}$, the relative density reached $98 \%$ during

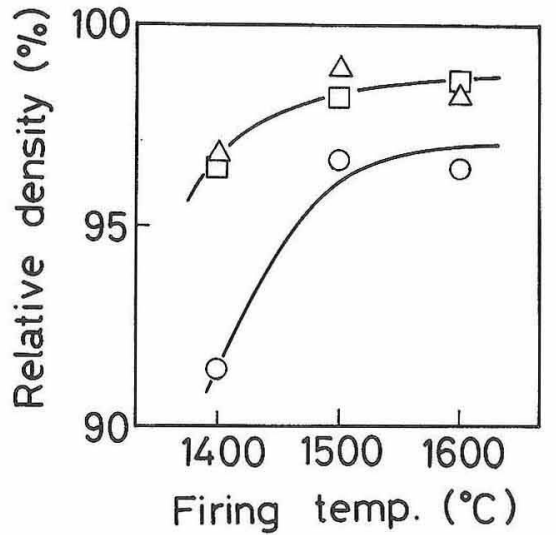

Fig. 2. Relative density of sintered body of carbon filament-free PSZ and firing temperature. Firing time $=2 \mathrm{~h}$.

CIP pressure $\left(\mathrm{t} / \mathrm{cm}^{2}\right)$ :

; no CIPed, $\triangle ; 1.5, \square ; 3.0$
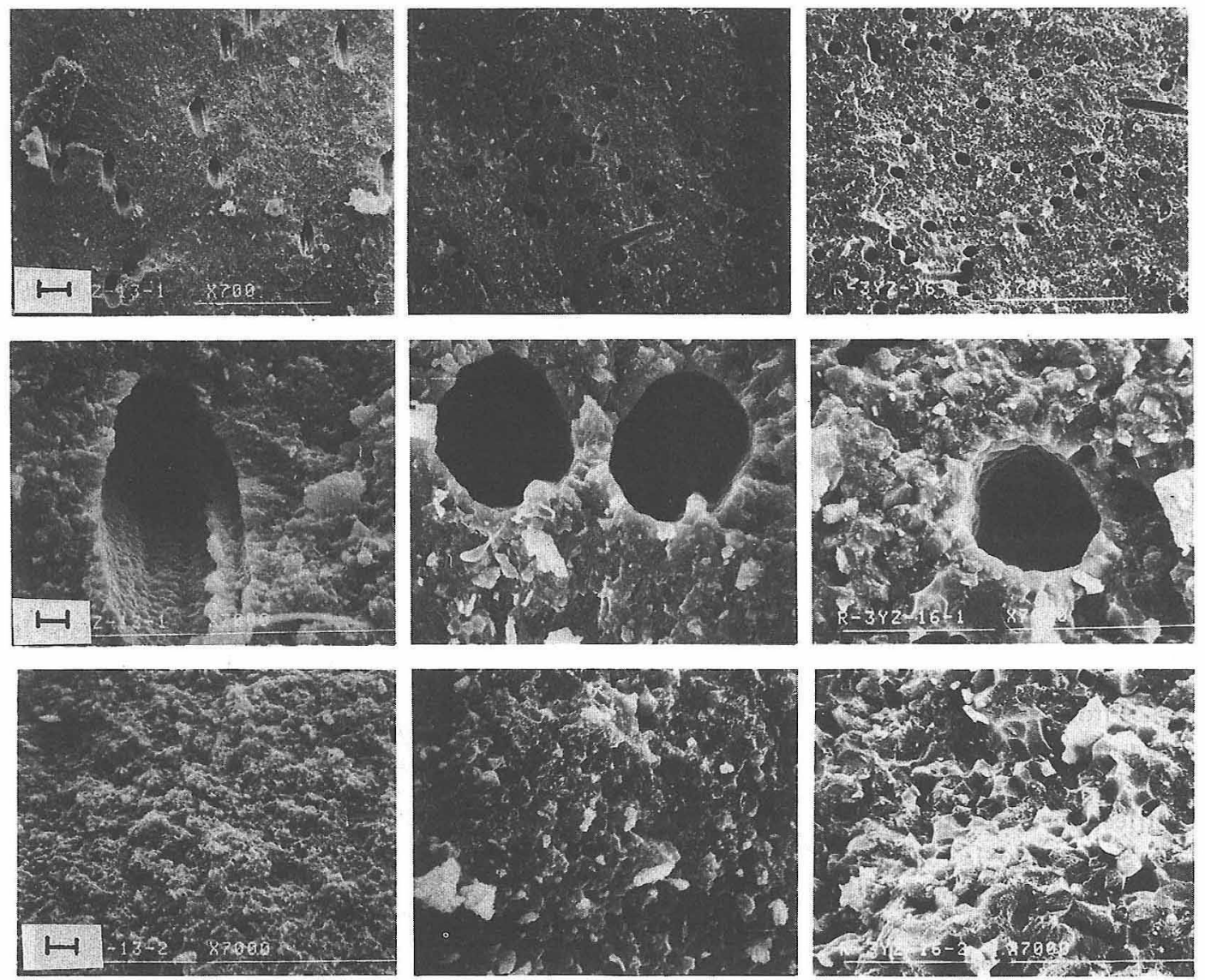

Fig. 3. Fracture surface of sintered bodies.

Samples were CIPed at $3.0 \mathrm{t} / \mathrm{cm}^{2}$ and fired for $2 \mathrm{~h}$ in air.

Sintering temperature :

A ; $1400^{\circ} \mathrm{C}, \mathrm{B} ; 1500^{\circ} \mathrm{C}, \mathrm{C} ; 1600^{\circ} \mathrm{C}$

Sample and marker

Top ; Carbon filament-PSZ. Marker : $10 \mu \mathrm{m}$

Middle; Carbon filament-PSZ. Marker : $1 \mu \mathrm{m}$

Bottom; Carbon filament-free PSZ. Marker : $1 \mu \mathrm{m}$ 
the heating and increased to $99 \%$ by additional 1 or $2 \mathrm{~h}$ heating at $1500^{\circ} \mathrm{C}$.

Acknowledgement The authors are grateful to Prof. I
Mochida for providing the carbon fiber Toreca.

Reference

1) A. Kato and H. Mizumoto, Ceramics International, 12 (2) $(1986)$ 